\title{
National INSPIRE Geoportal of the Czech Republic
}

\author{
Jan Prášek ${ }^{1}$, Jiří Valta ${ }^{1}$, and Jiří Hřebíček ${ }^{2}$ \\ ${ }^{1}$ Czech Environmental Information Agency, Vršovická 1442/65 \\ 10010 Praha 10, Czech Republic \\ ${ }^{2}$ Masaryk University, Institute of Biostatistics and Analyses \\ Kotlářská 2, 61137 Brno, Czech Republic \\ \{jan.prasek,jiri.valta\}@cenia.cz, hrebicek@iba.muni.cz
}

\begin{abstract}
Environmental information systems of the Czech Republic's Ministry of Environment have been developed since 1990. Creation of the National Information System to Collect and Evaluate Information on Environmental Pollution began in 2010. This project has been co-financed by the European Regional Development Fund. The project is split into three parts: (a) Integrated Reporting System (ISPOP); (b) Environmental helpdesk (EnviHELP) and (c) National INSPIRE Geoportal (Geoportal), which were developed in 2010-2013. In this article, Geoportal as national implementation of the INSPIRE Directive in the Czech Republic is presented in more detail including several usage examples.
\end{abstract}

Keywords: INSPIRE, ISPOP, EnviHELP, National INSPIRE Geoportal, GIS, CENIA.

\section{Introduction}

Environmental Information Systems (EIS) deal with processing, retrieval and presentation of environmental data and information. In the Czech Republic, European Union (EU) and the World, we are witnessing the creation of large-scale information and communication infrastructures. In the Czech Republic, EIS in public administration have been under development since the beginning of 1990 [1]. The Act No. 2/1969 Coll., on the establishment of ministries and other central state administration bodies of the Czech Republic (Article $4 \S 19$ ), provides that the Ministry of Environment (MoE) of the Czech Republic secures and manages development of the Single Environmental Information System (JISŽP), including overall monitoring of the entire Czech Republic. The information system (JISŽP) was defined by the MoE and consolidated including all non-operational information systems of MoE, its infrastructure and management systems [1-2].

In 2008, the MoE approved the Information Strategy of MoE and JSŽIP for the years 2008-2010 which focused on the importance of achieving interoperability within the EIS of MoE, the efficient management of environmental information content and information flow (from data monitoring and creation through their acquisition, validation, evaluation and presentation of highly aggregated information), in order to achieve a high level of electronic services in public administration 
(eGovernment) and also to support information provision by the services and to evaluate effectiveness of the policy instruments in environmental protection [2-3].

The basic objective of the Register of rights and obligations (RPP) of the Basic public administration registers within eGovernment [4] is to facilitate for citizens, companies and other entities the communication with the authorities. The RPP also contains their rights and obligations concerning environmental protection, including MoE agendas in JISŽP. At the same time, public authorities have to ensure a safe, efficient and transparent exchange of accurate and up-to-date environmental data for all the entities [2].

Focusing on a strategic approach related to the development, JISŽP emphasis is on achieving a high level of electronic services (eGovernment) and building up support for information services, to evaluate the effectiveness of policy instruments for environmental protection.

JISŽP Development Council, an advisory board of the minister of environment, is the institutional component to ensure data and access to information. To put this in practice, various application tools (ICT tools) have been gradually created within several individual projects in the respective MoE departments.

Development of the National Information System to Collect and Evaluate Information on Environmental Pollution (CISAŽP), which was co-financed by the European Regional Development Fund (ERDF), began in 2010 [6]. CISAŽP supported the implementation of Shared Environmental Information System (SEIS) and eEnvironment [7] in the Czech Republic. The main users of the new CISAŽP are the entities subject to environmental laws and public authorities. The aggregated environmental data and other information, however, will have to access to the public. The advantages and benefits of CISAŽP consist in a substantial increase of transparency, consistency and efficient communication between the Ministry of Environment and entrepreneurs, the authorities and the public.

CISAŽP consists of three main parts:

- Integrated reporting system (ISPOP) [8];

- Environmental helpdesk (EnviHELP) [9];

- National INSPIRE Geoportal (Geoportal) [10].

CISAŽP outputs allow computerization of administrative agendas throughout the environmental sector, simplifying considerably the reporting obligations and state administration. All information which enters the CISAŽP system is analyzed, evaluated comprehensively and placed into a broader context, taking into account the economic and social aspects and constraints. The outputs form an important basis and starting point for the formulation of priorities and objectives to protect and improve the environment in the Czech Republic.

The Czech Environmental Information Agency (CENIA) is in charge of development and technical operations related to CISAŽP.

The main users of CISAŽP are governmental institutions, professionals and the general public.

Other EIS projects were developed in the Czech Republic: IRZ (Integrated Pollution Register) [11]; CITES (Convention on International Trade in Endangered Species 
of Wild Fauna and Flora) register [12]; ISOH (Waste management information system) [13]; ISOP (Information system of nature conservancy) [14] and geological IS, e.g. Czech Geological Survey [15].

Formally, these EIS are reflected in a new concept of the Information Strategy of $M o E$ [5], the attestation of which took place in November 2012.

In the following text, we briefly introduce the ISPOP and EnviHELP systems and describe the National INSPIRE Geoportal in more detail.

\section{Integrated Reporting System (ISPOP)}

Environmental legislation of the Czech Republic (in compliance with the European Union (EU) legislation) imposes on economic entities (organizations, companies, enterprises, etc.) the duty to notify public authorities of their activities' environmental impacts.

These entities are thus becoming the declarants of environmental records. Their notification duty is provided for by the relevant environmental legislation of the Czech Republic, which obliges them to keep records and to report. The declarants'

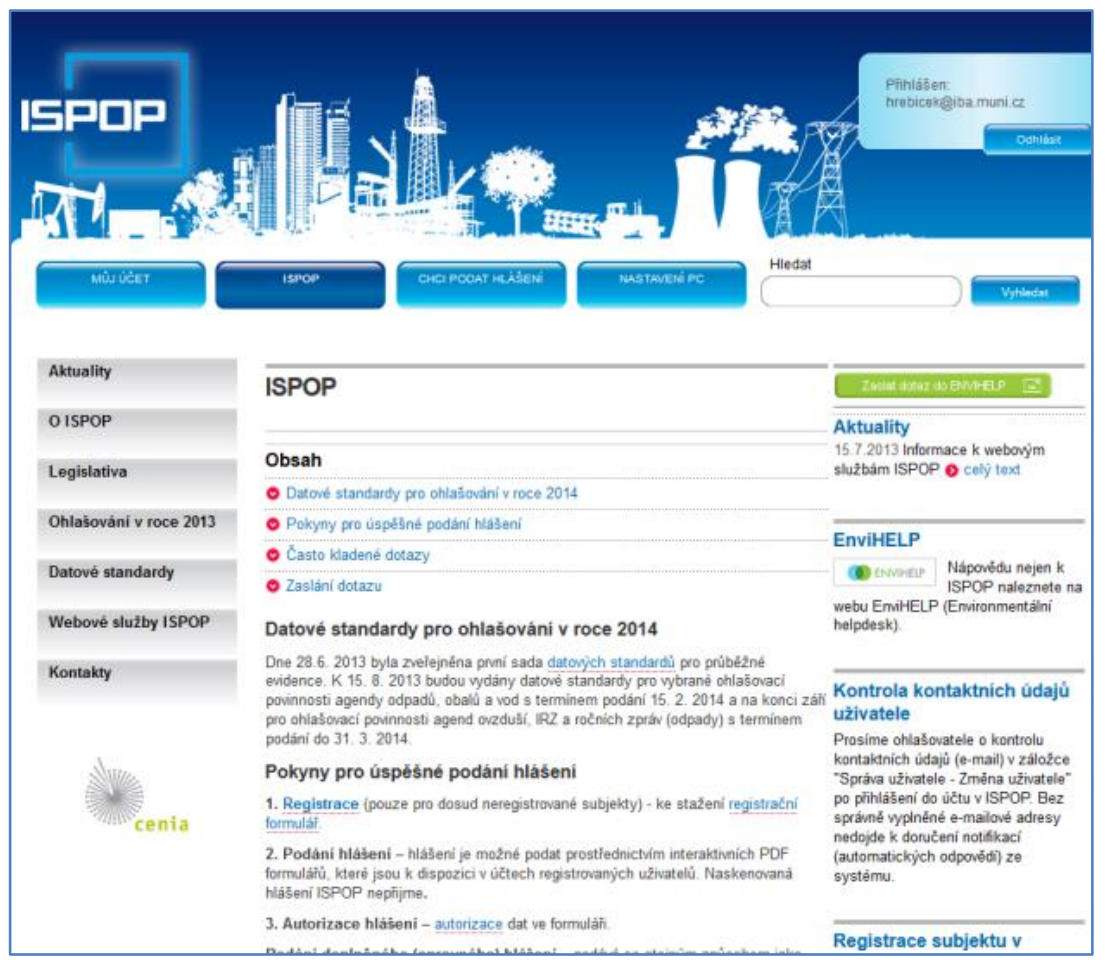

Fig. 1. Basic ISPOP website (Source [8]) 
duties include submitting of relevant environmental data, information and messages to the respective public authorities and institutions. This mainly includes primary environmental data such as those concerning air pollution, water pollution, waste, soil pollution, waste electrical and electronic equipment, car wrecks etc., which are processed and reported to the CENIA SEIS data centres.

ISPOP makes it possible to incorporate a reception of selected environmental reports (reporting obligations) in electronic format and also to distribute environmental reports to relevant institutions and public authorities including data flows to the SEIS data centres [6]. Operation of ISPOP was launched on $1^{\text {th }}$ January 2010 . The Ministry of Environment is the founder of ISPOP and it is also responsible for the forms to be filled in within the single reporting obligations. Technical operation and development of ISPOP is ensured by CENIA.

The ISPOP's main objective is to create a universal data input gateway providing the incoming data files in a specified standardized format. It controls distribution of the target processing systems. ISPOP must handle both the management reports submitted in a form of environmental records and archiving and evaluation of their content (in cooperation with other related systems). The ISPOP architecture was structured to ensure flexibility in terms of expansion to the other input agendas and also to guarantee, inter alia, compliance with updated environmental legislative obligations.

\section{Environmental Helpdesk - EnviHELP}

EnviHELP provides support in a particular operating state, e.g. administration for incumbents fulfilling the reporting obligations under the Act No. 25/2008 Coll., as well as business communities and the general public in providing environmental information in relation to the Act No. 123/1998 Coll., public access to environmental information and the Aarhus Convention.

Knowledge basis of the Environmental Helpdesk is under preparation at present. It aims at collecting the maximum available information and methodological materials on environmental issues. Currently, it comprises:

- about 500 items of the following types: law, regulations, government regulations, etc.;

- about 1,400 terms related to the environment;

- about 300 life situations;

- 350 agendas arising from legislation;

- 400 most frequently asked questions concerning life situations and MoE agendas;

- 700 inputs and outputs of MoE agendas or life situations and other contexts;

- about 500 objects, especially guidance and reporting support for ISPOP. 


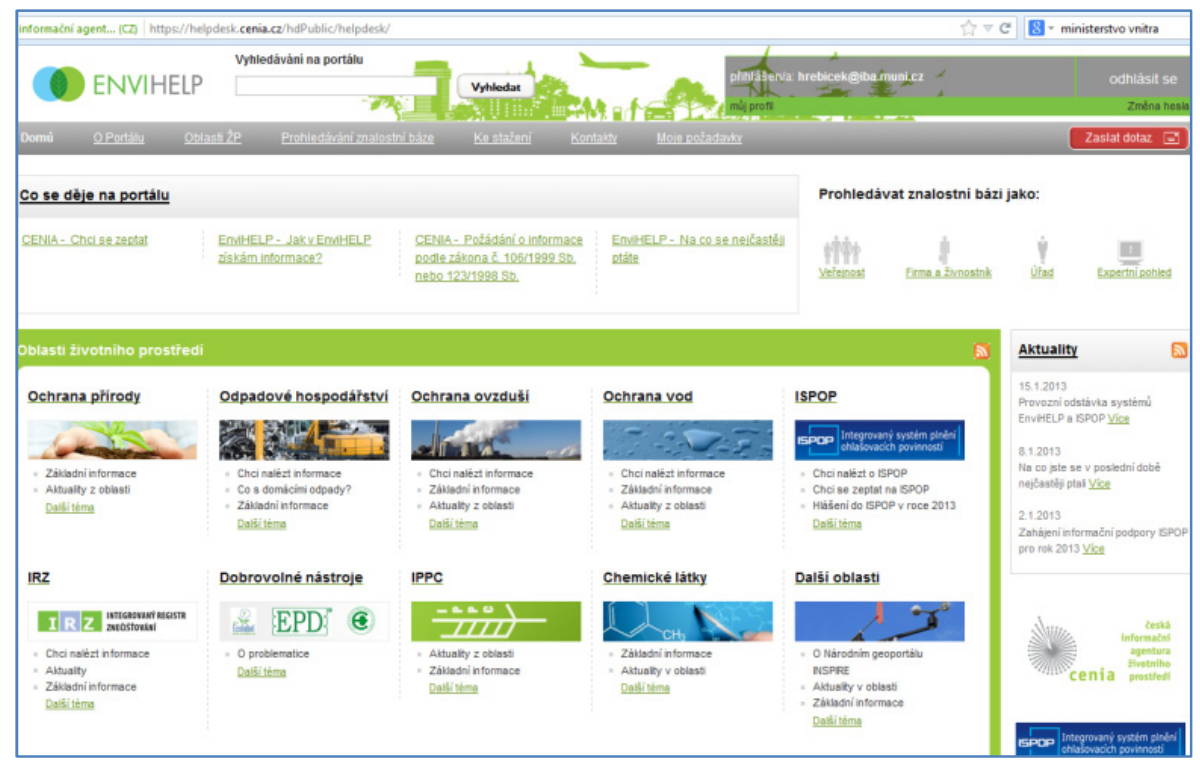

Fig. 2. Environmental helpdesk (EnviHELP) website (Source [9])

\section{National INSPIRE Geoportal}

At present, the amount of GIS (Geographical Information Systems) users is growing continuously. This technology improves work and decision-making at both national and local government level. The INSPIRE (Infrastructure for Spatial Information in Europe) initiative of the European Commission (EC), described in the Directive No. 2007/2/EC, specified the setup of a spatial data infrastructure within the Community (the INSPIRE Directive). This Directive aims at creating a European legislative framework which is needed to build a European Spatial Data Infrastructure (SDI). It lays down general rules for the establishment of a European SDI, in particular to support environmental policies and policies that affect the environment.

INSPIRE employs the following basic principles to organize the European geoinformation infrastructure [16]:

- geo-information will be stored, managed and made available on one suitable level;

- geo-information coming from different sources in the European Union can be combined in a consistent manner and exchanged between different users and applications;

- geo-information that has been collected from one public sector level can be exchanged with other public sector levels;

- geo-information will be made available in such a way that large-scale use of the system will not be unnecessarily impeded; 
- any available geo-information can easily be looked up, and the suitability and user conditions can easily be checked.

EU Member States are providing discovery and view services according to the INSPIRE Regulation on Network Services through the INSPIRE Geoportal [17] which was launched in November 2011. The main objective of INSPIRE is to make more high-quality and standardized spatial information for the development and implementation of EU policies at all levels of the EU Member States. The INSPIRE Geoportal provides the means to search for spatial data sets and spatial data services, and subject to access restrictions, to view spatial data sets from the EU Member States within the framework of the INSPIRE Directive.

The INSPIRE Directive was transposed to the Czech Republic's legislation through the amended Act No. 123/1998 Coll., on public access to environmental information, which entered into force on 23 October 2009. On the basis of this Act, the National INSPIRE Geoportal (Figure 3) was established to allow the general public access to spatial data relating to at least one of the topics of the INSPIRE Directive attachments.

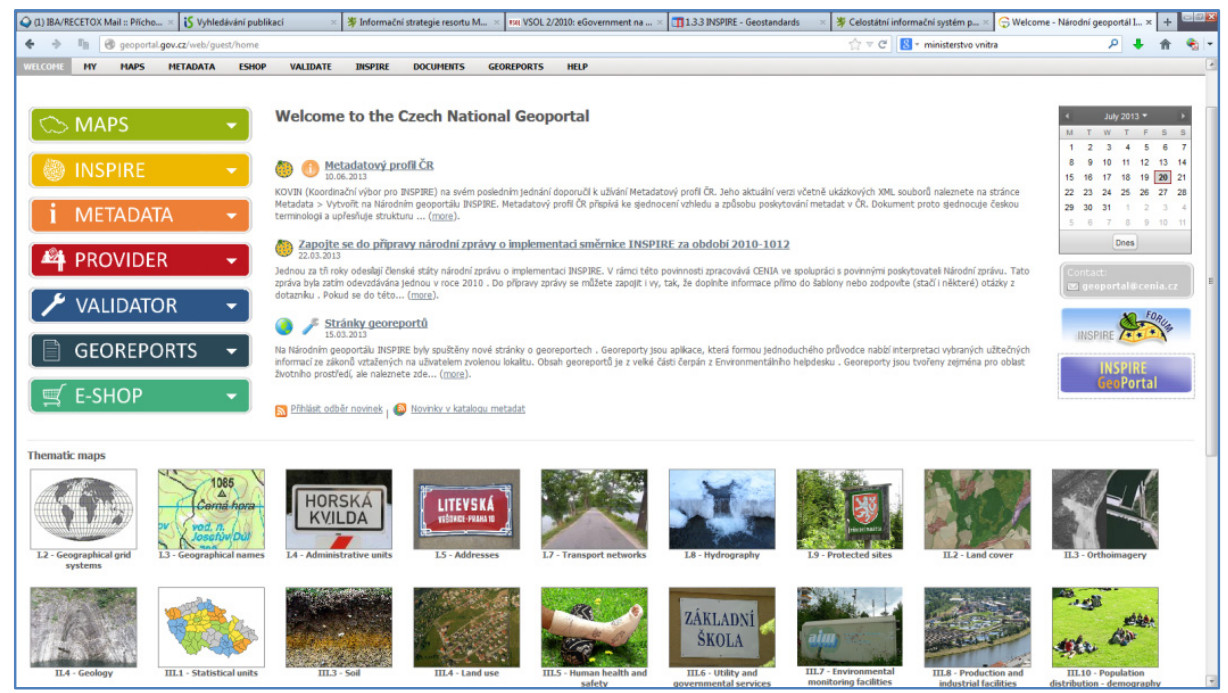

Fig. 3. Homepage of the Czech National INSPIRE Geoportal (Source [6])

The construction of Czech National INSPIRE Geoportal (i.e. Geoportal) made available the current and validated spatial data concerning the Czech Republic to improve the design, implementation and monitoring of environmental policies at the national, regional and local levels. The Geoportal project is also designed to enable solutions to life situations by linking to the EnviHELP knowledge base within Georeport generation. Geoportal was implemented during the period 2009-2013 and it aims at providing more transparency, consistency and efficiency to the communication 
between entrepreneurs, government and the public on one side and the MoE on the other, and also at fostering implementation of eEnvironment in the Czech Republic.

\subsection{Technical Solutions to Geoportal}

Geoportal is based on the ICT solutions ESRI, ArcGIS10.x Server for Server Enterprise Advanced (4 cores) [18]. The portal solution is built on the open source applications company DxoLogicLiferay Enterprise [19].

Geoportal uses information services to connect CENIA to map servers and other data providers, see Figure 4.

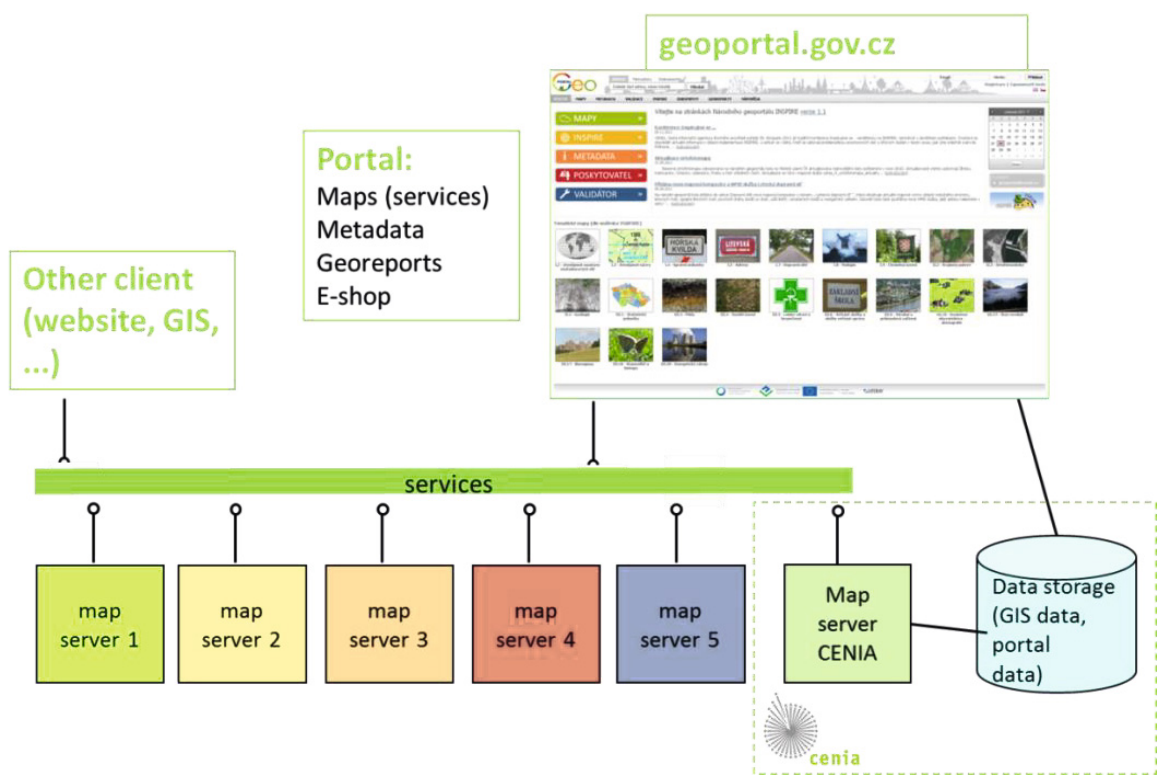

Fig. 4. Geoportal Architecture (Source: authors)

\subsection{Geoportal Services}

Geoportal services are provided on a subscription basis. For unregistered users, only the essential basic tools of the Geoportal are available. An ID-based registration of a Geoportal's user is required for all the other Geoportal activities and services. Registration allows users to store their own map compositions, to download data (via eshop), to create and store metadata at the metadata server and much more. If providing data, metadata, data monitoring, etc., the users must also include, in addition to the registration, a verification of the data provided, even if the activity is performed by an authorised person, organization or company.

All data included in Geoportal documents contain Metadata; they are used to perform different operations to search for or create the user's own metadata according to 
a national or INSPIRE profile using the metadata editor. Metadata can also be imported into the user's own metadata records but they must subsequently be validated against the supported profiles.

Geoportal also lets users use their own services (catalogue, viewing, ...). These services can be registered within Geoportal. This function is available only to the registered users, and only for services that are equipped with metadata.

The system also allows the registered users to make their own data accessible. The data can be uploaded to Geoportal and the administrators can then create a service or can be entrusted with publishing the data.

According to the INSPIRE Directive, each data and service provider is annually required to fill in details about their data sets and services. For this purpose, a monitoring tool is being operated. Every provider, from early January to late February, completes the required data for the previous calendar year.

Current map layers published by Geoportal are as follows [9]:

- Cadastral maps:

- Land Register;

- definition points of parcels;

- Land Cadastre.

- Topographic maps of the Czech Office for Surveying, Mapping and Cadastre;

- Main Basis of Geographical Maps of the Czech Republic (ZABAGED ®);

- Digital model area (DMÚ25);

- Orthophoto maps (historical);

- Orthophoto maps (current);

- III. Military Survey (1870s and 1880s, scale 1: 25,000), a new height, contours and dimensions;

- II. Military Survey (1806 - 1869 in Austria-Hungary, scale 1:28 800);

- Military maps (raster);

- Road maps.

In Geoportal menu, Home is made up of a menu containing the favoured map tasks according to INSPIRE categories, see Figure 3.

The Geoportal map window consists of a chart and menu displaying various maps and layers that can be seen, added or removed. The menu is also a guide post to metadata of the individual map layers, see Figure 5.

Maps displayed at the National INSPIRE Geoportal are also available in the form of map services, which can be used in so-called thick clients (software applications) for other purposes. Map services are offered as standard WMS and are also available via Simple Object Access Protocol (SOAP) services of ESRI ArcGIS Server [18]. Both types of services have the same names and data visualized in the same way. 


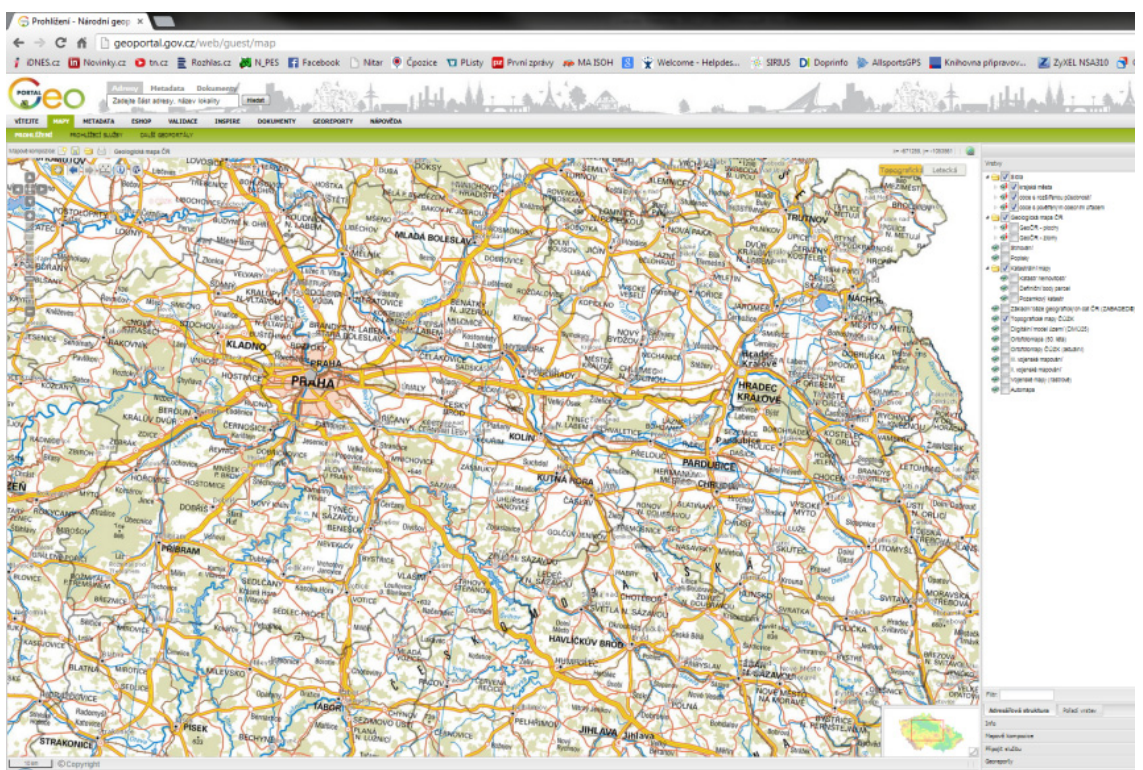

Fig. 5. Map Window (Source: authors)

The individual objects in spatial compositions can obtain a detailed description of their attributes, such as information from air quality monitoring stations, Figure 6.

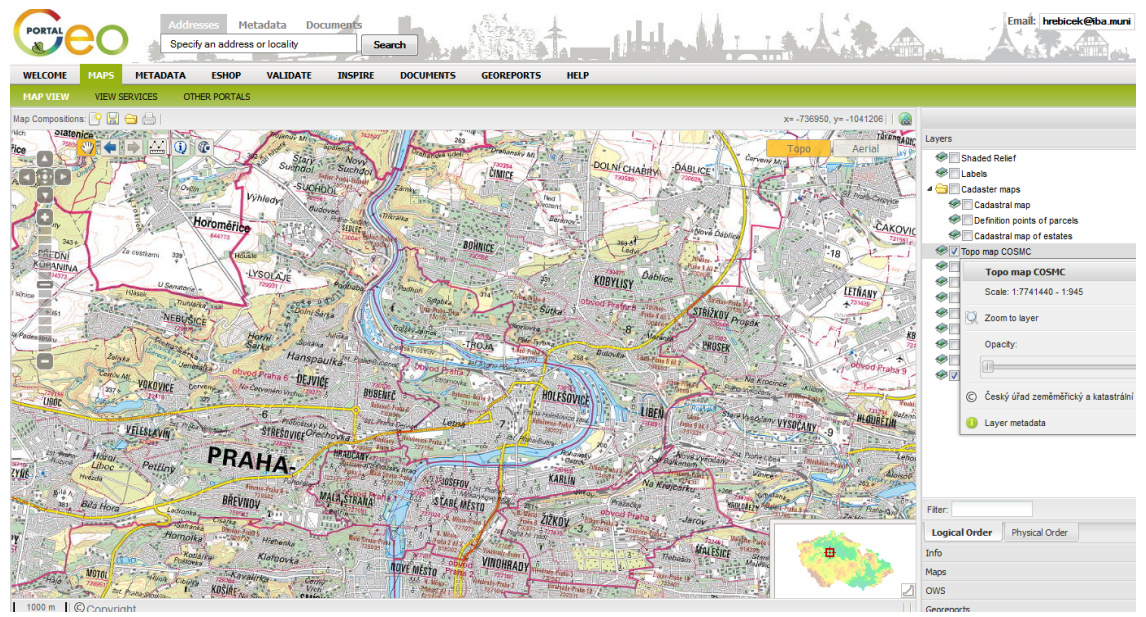

Fig. 6. Detail of Attributes (Source: authors)

\section{$5 \quad$ Map Examples}

In this section we present several interesting examples of how to use Geoportal. 


\subsection{Noise Map of Prague}

The noise map of Prague is based on the evaluation of measured noise values in different parts of the metropolitan area. Currently available data are extrapolated from the evaluation of noise indicators $\operatorname{Ln}(\mathrm{dB})$ and $\operatorname{Ldvn}(\mathrm{dB})$, see Figure 7.

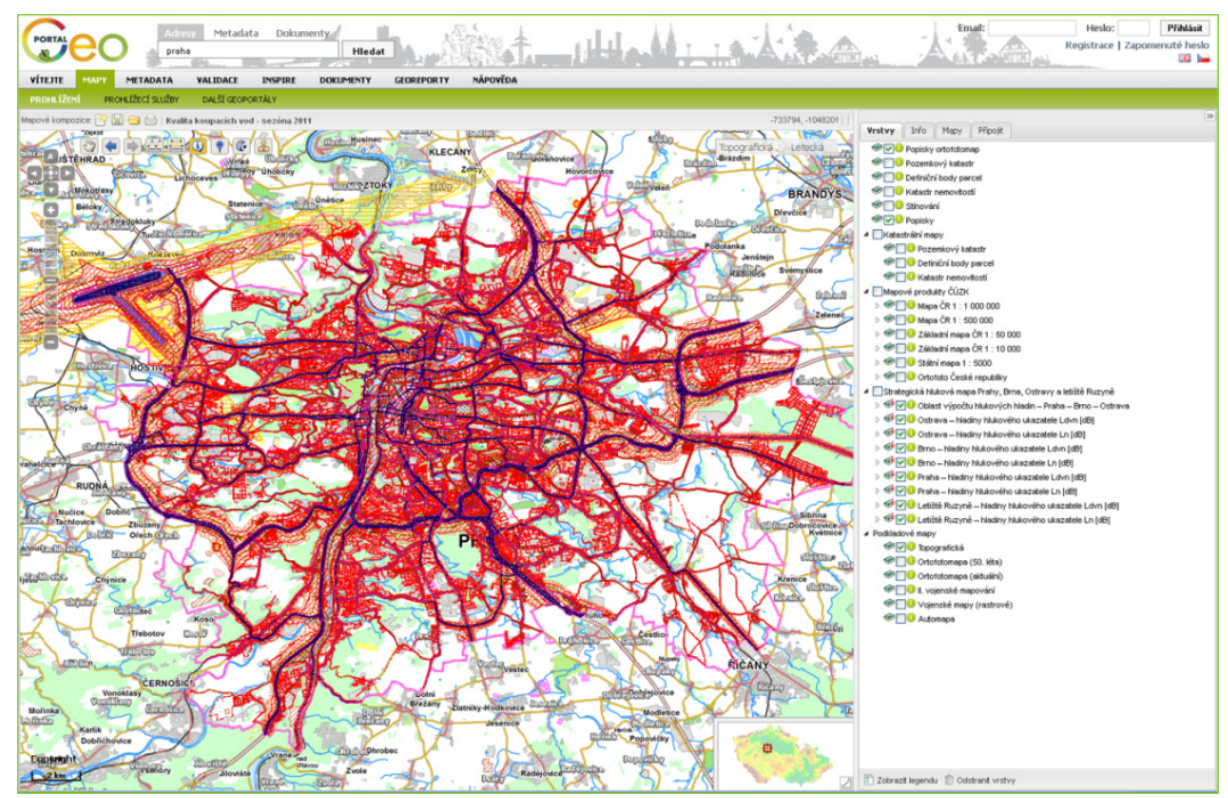

Fig. 7. Noise Map of Prague (Source: authors)

\subsection{Geological Map of the Czech Republic}

The task of the Czech Geological Survey (CGS) [20], established in 1919, is to provide the national geological services for the Czech Republic. The CGS is the national organization with the statutory responsibility to gather, store and interpret geological information so that the authorities can take appropriate decisions about national economic and environmental issues. It provides the results of systematic regional geological mapping and investigation to all interested persons. It also performs related tasks as required by the MoE on the basis of the Act No. 62/1988, on geological work. This involves the collection, processing and provision of information regarding geological structure, protection and use of mineral and groundwater resources, and also concerning geohazards. The CGS map portal is connected to Geoportal.

The Geological Map of the Czech Republic (Digital Geo-atlas of the Czech Republic - GEOČR 500, see Figure 8) developed by CGS provides 11 maps covering different geological and scientific topics, arising mostly from the original analogue data at the scale 1:500,000 (Geological Map, Radiometric Map, Map of Radon Risks, Map of Mineral Water, Gravimetric Map, Digital Elevation Map, Satellite Map, Map of Land Cover, Topographical Map). Individual maps form a unique GIS, which is also made in the three coordinate systems: S-JTSK, S-42, and geographic coordinates. 


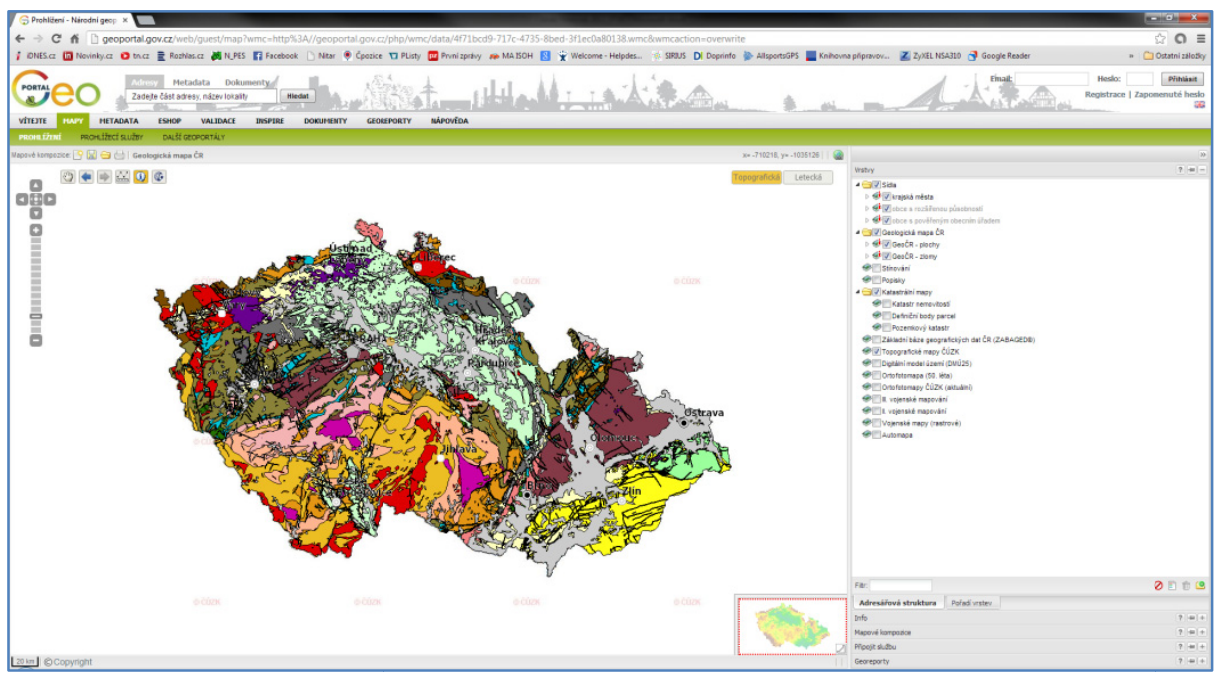

Fig. 8. Geological Map of the Czech Republic (Source: authors)

\subsection{Historical and Present-Day Orthophoto Maps}

Within the methodological section (Stage 1) of the project National Inventory of Contaminated Sites (NIKM) [21], an orthophoto map of the Czech Republic was created from historical images collected within the first nationwide aerial photographing

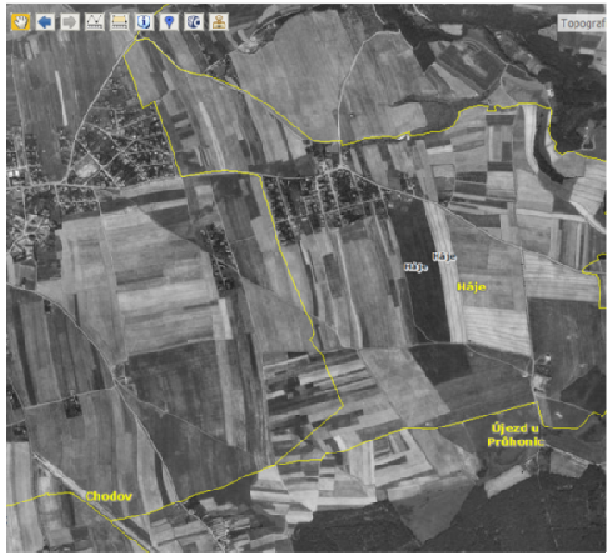

1952

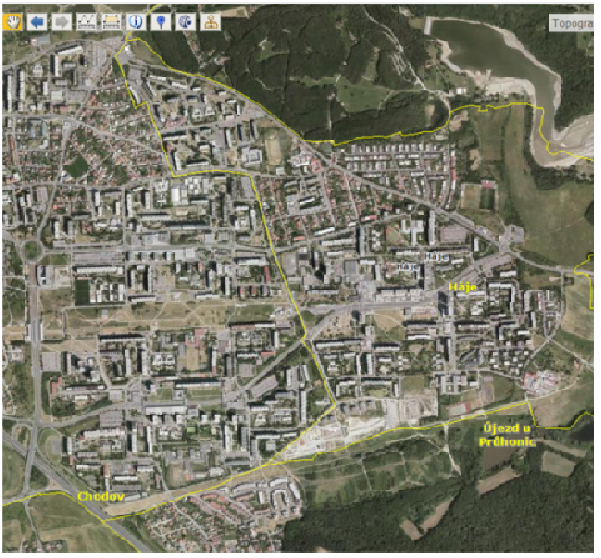

2010

Fig. 9. Comparing orthophoto maps of 1952 and 2010 - development of the settlement (Source: authors) 
dating back to 1950s. The company Geodis BRNO $\operatorname{Ltd}^{1}$ has processed the source materials (aerial images provided by the Military Geographic and Hydrometeorological Office (VGHMÚř) in Dobruška ${ }^{2}$ ) and supplied the historical orthophoto maps.The current orthophoto map is provided via the browser-based services WMTSORTOFOTO as a public viewing service related to the data from the orthophoto map of the Czech Republic. In order to optimise the speed, the data are provided in a form of map tiles. The orthophoto data service covers the entire usable range of scaling, i.e. including small scales. The service meets the technical guidance for INSPIRE View Service v. 3.1 [22] and is compliant with the standard OGC WMTS 1.0.0 ${ }^{3}$. To compare development of settlement captured in the maps of 1952 and 2010, see Figure 9.

\subsection{The 2006 Floods}

On the basis of evaluation of the measurement data, it is possible to see the area which the Elbe River flooded on April 3, 2006 (Figure10).

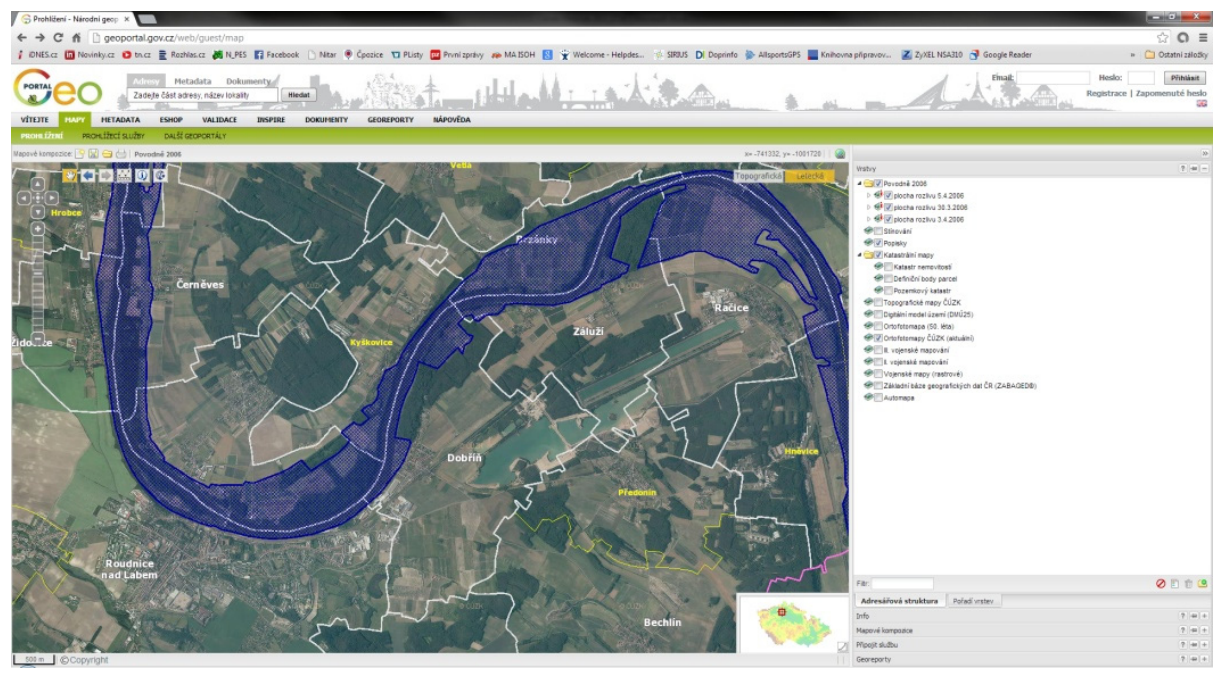

Fig. 10. Area flooded by the Elbe River on April 3, 2006 (Source: authors)

\section{Georeports}

Georeports represent an application of Geoportal, which offers, in a simple form, interpretation of selected useful information based on data related to a selected location. To create a Georeport output, the users simply choose a Georeport topic and select an area of their interest on the map.

\footnotetext{
1 http://sluzby.geodis.cz/products/coloured-orthophotomapof-the-czech-republic?lang $=2$

2 http://www.geoservice.army.cz/htm/s_urad.html

3 http: //www. opengeospatial.org/standards/wmts
} 
In a Georeport, the map section with the results of the spatial data analyses of the selected areas is accompanied by text. In the text part, the Georeport contains a final list of relevant authority offices which concern the chosen topic in the locality, and information about possible deadlines, permits, forms and fees is also provided. The resulting, automatically generated Georeport takes the form of a PDF document that can be viewed, saved, and sent to an e-mail address.

E-shop is a further application of Geoportal and it provides access to paid services consisting of:

- Data sharing/providing tool (including licensing).

- Providers themselves decide to whom they wish to provide the data and under what conditions.

- Geoportal output module exports the desired data to the approved applicants.

- RSS feeds also serve without any fee, in the form of a "click" license.

\section{Conclusion}

Development of CISAŽP project of the MoE began in 2010; it has been co-financed by the European Regional Development Fund during 2010-2013. Environmental information is generated by CISAŽP in its three main components: IS ISPOP, EnviHELP and Geoportal. IS ISPOP is used for electronic reporting of mandatory data from environmental polluters. The environmental helpdesk EnviHELP provides support to users of the subsystems within the project CISAŽP. EnviHELP is designed to serve as the main help desk platform managed by the MoE.

Geoportal provides updated and validated spatial data to improve the design, implementation and monitoring of environmental policies at the national, regional and local levels. It includes ICT tools for receiving and validating spatial data and services from statutory and other providers. It also enables display and publication based on standardized service creation, management and retrieval using metadata, transformation and loading of data and it guarantees payment for the data.

It can also be linked to EnviHELP knowledge base to solve different life situations within generating Georeports. Geoportal receives in average 4,300 visits per day by users who download about $44.6 \mathrm{~GB}$ of data.

\section{References}

1. Hřebíček, J.: Globale Umweltinformationssysteme in internationalen Masstab. In: Internationales Umweltmanagement, Band II: Umweltmanagementinstrumente und - systeme. Gabler Verlag, Wiesbaden (2003)

2. Hřebíček, J., Kubásek, M.: Environmentální informační systémy (Environmental information systems). Akademické nakladatelství CERM, Brno (2011),

http: //www.iba.muni.cz/res/file/ucebnice/

hrebicek-environmentalni-informacni-systemy.pdf 
3. Bízková, R.: eGovernment na Ministerstvu životního prostředí (eGovernment at the Ministry of Environment) (2010), http: / / vsol . obce.cz / clanek. asp?id=2 010209

4. Základní registry veřejné správy (Basic public administration registers), http: / / www.mvcr.cz/clanek/zakladni-registry-zakladniregistry-verejne-spravy . aspx

5. Informační strategie Ministerstva životního prostředí (Information strategy of the Ministry of Environment), http://www.mzp.cz/cz/informacni_strategie

6. Projekt CISAŽP, http://www.mzp.cz/cz/projekt_cisazp

7. Hřebíček, J., Pillmann, W.: eEnvironment: Reality and Challenges for eEnvironment Implementation in Europe. In: Hřebíček, J., Schimak, G., Denzer, R. (eds.) ISESS 2011. IFIP AICT, vol. 359, pp. 1-14. Springer, Heidelberg (2011)

8. Integrated reporting compliance, http://www. ispop.cz

9. Environmental help desk, http://helpdesk.cenia.cz

10. Geoportal, http://geoportal.gov.cz

11. Integrated register pollution, http://www.irz.cz/

12. CITES, http://www.mzp.cz/en/cites

13. ISOH, http://www1. cenia.cz/www/odpady/isoh

14. ISOP, http://portal. nature.cz/publik_syst/ctihtmlpage.php?what= $3 \&$ nabidka=hlavni

15. Czech Geological Survey, http: / / www.geology.cz/extranet-eng

16. INSPIRE standards, http://geostandards.geonovum.nl/index.php/1.3.3_INSPIRE

17. INSPIRE geoportal, http: //inspire-geoportal .ec.europa.eu/

18. ArcGIS for Server, http://www.esri.com/software/arcgis/arcgisserver

19. DxoLogicLiferay Enterprise, http://www. doxologic.com/produkty/liferay-portal

20. Czech Geological Survey, http: / /www.geology.cz/extranet-eng/sgs

21. Suchánek, Z.: NIKM Project. The national inventory of contaminated sites., http://wWw. cenia.cz/_C12572160037AA0F.nsf/pid/CPRJ7RCKSQQ7/ FILE/GEO 2 0GEOSS\%20Seminar\%20130212\%20CENIA.pdf

22. Technical Guidance for the implementation of INSPIRE View Services, http://inspire.jrc.ec.europa.eu/documents/Network_Services/ TechnicalGuidance_ViewServices_v3.0.pdf 